\title{
$\mathrm{HPLC/ESI-MS/MS에} \mathrm{의한} \mathrm{먹는물(정수)} \mathrm{중} \mathrm{의약물질의} \mathrm{분석}$ \\ 박미선 · 김병주 · 명승운 \\ 경기대학교 화학과 \\ (2010. 7. 28. 접수, 2010. 9. 20. 승인)
}

\section{The analysis of pharmaceuticals in drinking water by HPLC/ESI-MS/MS}

\author{
Mi Sun Park, Byung-Joo Kim and Seung-Woon Myung ${ }^{\star}$ \\ Department of Chemistry, Kyonggi University, Iui-dong, Yeongtong-gu, Suwon, Gyeonggi, 443-760, Korea \\ (Received July 28, 2010; Accepted September 20, 2010)
}

\begin{abstract}
요 약: 먹는물(정수) 중에 잔류하는 버지니아마이신을 비롯한 macrolide 계열 의약물질 3종과 시메티딘 을 동시에 정량 및 정성 분석하는 방법을 확립하였다. HLB 카트리지를 사용하여 분석물질을 추출/정제 및 농축한 후, HPLC/ESI-MS/MS를 이용하여 4종의 물질들을 효과적으로 분리하고 감도 좋게 검출할 수 있었다. 정량분석을 위해서 $0.01 \sim 2.0 \mathrm{ng} / \mathrm{mL}$ 범위에서 $\mathrm{r}^{2}=0.995$ 이상의 높은 직선성을 나타내는 검량선을 얻었으며, 시메티딘(37.7 48.1\%)을 제외한 macrolide 계열 3종 의약물질은 64.7 118.1\% 범위의 양호한 회 수율을 나타내었다. 바탕 정수에 소량 첨가하여 얻은 분석방법의 검출한계와 정량한계는 각각 1.6 74.8 $\mathrm{pg} / \mathrm{mL}$ 와 5.5 249.7 $\mathrm{pg} / \mathrm{mL}$ 범위의 높은 감도를 나타내었다.

Abstract: The analytical method of four pharmaceuticals (virginiamycin, erythromycin, tylosin and cimetidine) in drinking water was developed. Effective simultaneous sample clean-up and extraction by solid-phase extraction (SPE) using HLB cartridge prior to LC/ESI-MS/MS analysis were performed. A linear correlation observed in the calibration curves for drinking water in the range of $0.01 \sim 2.0 \mathrm{ng} / \mathrm{mL}$ showed above $\mathrm{r}^{2}=0.995$. Absolute recovery was in the range of $64.7 \sim 118.1 \%$ (except cimetidine (37.7 48.1\%)). Limit of detection (LOD) and limit of quantitation (LOQ) in spiked drinking water matrix were in the range of $1.6 \sim 74.8 \mathrm{pg} / \mathrm{mL}$ and $5.5 \sim 249.7 \mathrm{pg} / \mathrm{mL}$, respectively. The established method can be used to determine low $\mathrm{pg} / \mathrm{mL}$ levels of pharmaceuticals in the drinking water.
\end{abstract}

Key wards: macrolides, cimetidine, drinking water, LC/ESI-MS/MS

\section{1. 서 론}

사람과 동물의 질병치료의 목적으로 개발된 의약품 들은 소변이나 대변은 물론이며 의약품의 직접적인
폐기, 병원 폐기물 등 다양한 경로를 통해서 하천수, 토양 심지어는 먹는물(정수)에 까지 유입되어 생태환 경은 물론이며 인간에게 까지 영향을 미치고 있다. 환경중 잔류되는 의약물질이 새로운 오염물질로 대두

Corresponding author

Phone : +82-(0)31-249-9647 Fax : +82-(0)31-249-9647

E-mail : swmyung@kgu.ac.kr 
되기 시작하면서 미국, 프랑스, 독일, 영국, 캐나다 등 각국에서는 하수처리장 및 축산폐수처리장의 방류수 는 물론이고 하천수와 먹는물에서 항생제, 진통제, 호 르몬제, X-ray 조영제 등 다양한 종류의 의약물질이 검출되고 있음을 보고하고 있다.-3

우리나라에서도 일부 하수에서 콜레스테롤 저하제, 소염진통제, 해열제 등 의약물질이 검출되어 사회적 이슈가 되고 있으며 몇몇 자치단체에서는 의약품 수 거함을 사용하여 의약품들을 안전하게 수거하도록 하고 있다. 한강물과 서울의 4대 하수처리장의 물에 서도 카페인과 위궤양치료제 등의 의약물질이 검출 되고 있다. 2009년 조사에 의하면 위염 - 궤양치료제 인 시메티딘이 비교적 높은 농도인 $0.84 \mathrm{ng} / \mathrm{mL}$ (검출 된 하천수에서 평균)로 검출되었는데, 방류수에서의 검출률과 검출농도를 고려할 때 하수 및 축산폐수처 리장에서 의약물질의 제거효율이 낮은 것으로 나타 났다. ${ }^{4}$

본 연구에서 목표로 하고 있는 의약물질인 마크로 라이드(macrolides)계 항생물질들은 동물들의 호흡기 계 치료제 또는 성장촉진을 위한 사료첨가제 등으로
사용되고 있으나 인체에 독성효과나 과민반응을 유 발할 수 있고 내성균을 생성할 수 있는 것으로도 알 려져 있다.

타이로신(tylosin)과 버지니아마이신(virginiamycin) 은 HPLC/UV-vis를 사용하여 분석하기도 하지만 낮 은 농도까지 더 효과적으로 검출하기 위해서는 $\mathrm{LC} /$ $\mathrm{MS} / \mathrm{MS}$ 방법이 많이 사용되고 있으며, 에리스로마 이신(erythromycin)은 자외선-적외선 발색단이 강하 지 않아 LC/UV-vis 보다는 LC/MS/MS 방법을 많 이 사용하고 있다..$^{5-9}$ 시메티딘(cimetidine)의 경우 아직까지는 LC/MS/MS보다는 HPLC 방법이 일반 적이다. ${ }^{10-11}$

본 논문에서는 먹는물(정수) 중에 잔류하는 마크 로라이드계열 약물인 버지니아마이신, 에리스로마이 신, 타이로신 등 3종 의약물질과 시메티딘(Fig. 1)을 $\mathrm{LC} / \mathrm{MS} / \mathrm{MS}$ 를 사용하여 효과적이고 감도가 좋고 정 밀성이 높게 동시에 분석하는 방법(시료전처리 및 기기분석)을 확립하고자 하였다. 지금까지 발표된 문 헌들에서는 이들 4 종의 의약물질을 물 환경시료에서 동시 분석하는 방법이 발표된 적이 없기 때문에, 확

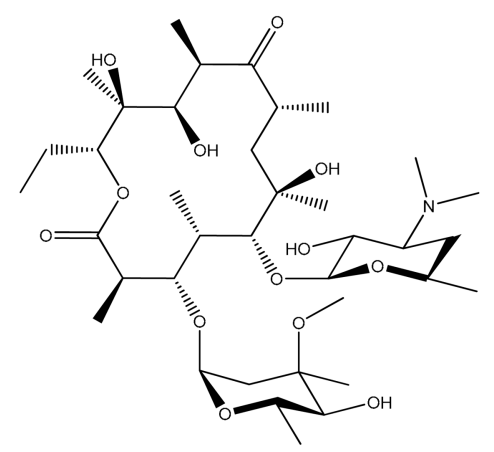

Erythromycin<smiles>CC(=O)c1coc(CC(=O)CC(O)/C=C(C)/C=C/CNC(=O)/C=C/C(C)C(OC(=O)C2=CCCN2)C(C)C)n1</smiles>

Virginiamycin

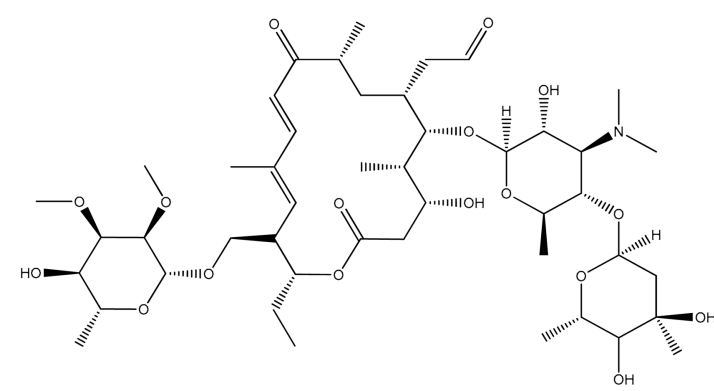

Tylosin

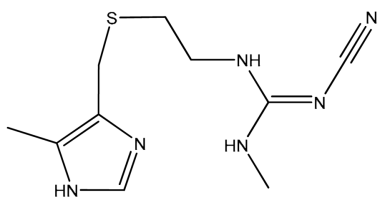

Cimetidine

Fig. 1. Chemical structures of pharmaceuticals. 
립된 분석법은 먹는물(정수)은 물론이며 하천수 중 에 잔류하는 의약물질의 모니터링에 있어서 기여할 것으로 본다.

\section{2. 실 험}

\section{1. 시약}

분석물질인 버지니아마이신, 에리스로마이신, 타이 로신, 시메티딘은 Sigma-Aldrich사(St Louis, MO, $\mathrm{USA}$ )에서 구입하였으며 정제용 내부표준물질(surrogate standard)인 에리스로마이신-2- ${ }^{13} \mathrm{C}$ 은 Cambridge isotope laboratories사(Andover, MA, USA) 제품을 사용하였고, 내부표준물질로 사용된 터부틸라진은 Fluka사(Seelze, Germany)의 고순도 시약을 사용하였다.

메탄올과 아세토나이트릴은 J.T. Baker사(NJ, USA)의 HPLC 등급 시약을 사용하였고, 황산은 Junsei사 (Tokyo, Japan), 암모늄아세테이트는 Merck사(Darmstadt, Germany) 제품을 사용하였으며, 증류수는 Milli-Q system을 통과한 3차 증류수를 사용하였다.

\section{2. 기기 및 장치}

LC/MS/MS는 Agilent 사(Palo Alto, CA, USA)의 Agilent 1200series HPLC와 Agilent 6410 Triple-quadrupole 텐뎀 질량분석기(Agilent Technologies, Palo Alto, CA, USA)를 사용하였다. HPLC에 사용된 컬럼 은 Eclipse Plus $\mathrm{C}_{18}(2.1 \times 100 \mathrm{~mm}, 3.5 \mu \mathrm{m}$; Waters, $\mathrm{USA}$ )이었다. 원심분리기는 한일과학사(Seoul, Korea) 의 Supra $22 \mathrm{~K}$ 를 사용하였으며 Whatman사(Maidstone, $\mathrm{UK})$ 의 $\mathrm{GF} / \mathrm{B}$ glass 여과지와 Life Sciences사(UK) 의 실린지 디스크 필터 $(0.45 \mu \mathrm{m}, 13 \mathrm{~mm})$ 를 사용하 였다.

고체상 추출(SPE) 카트리지는 Oasis HLB(Hydrophilic-Lipophilic Balance, $60 \mathrm{mg}, 3 \mathrm{cc}$ )로 Waters사(Milford, Massachusetts, USA)의 제품을 사용하였고 vacuum manifold는 Supelco사(Bellefonte, PA, USA)의 제품을 사용하였다. 질소농축기는 Caliper Lifescience사(Seattle, $\mathrm{WA}, \mathrm{USA}$ )의 TurboVap LV 농축기를 사용하였으며, vortex mixer는 Vision Scientific사(Bucheon, Korea)의 제품을 사용하였다.

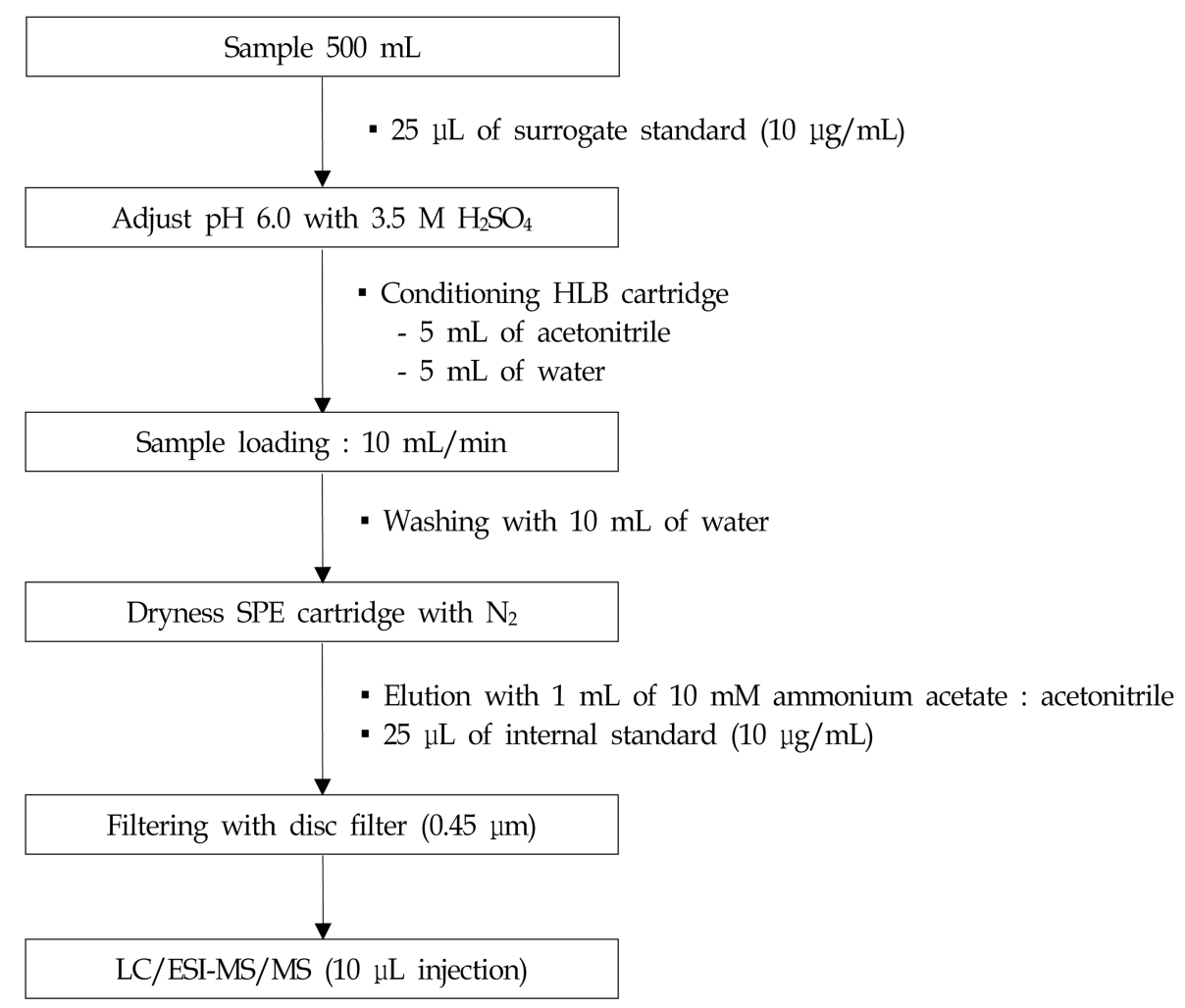

Fig. 2. Schematic diagram for the sample preparation of pharmaceuticals in drinking water. 
Table 1. Retention time, precursor ion and product ion of pharmaceuticals by LC/MS/MS

\begin{tabular}{lcccccc}
\hline \hline \multicolumn{1}{c}{ Pharmaceuticals } & $\begin{array}{c}\text { R.T. } \\
(\mathrm{min})\end{array}$ & $\begin{array}{c}\text { Precursor ion } \\
(\mathrm{m} / \mathrm{z})\end{array}$ & $\begin{array}{c}\text { Confirmation ion } \\
(\mathrm{m} / \mathrm{z})\end{array}$ & $\begin{array}{c}\text { Quantitation ion } \\
(\mathrm{m} / \mathrm{z})\end{array}$ & $\begin{array}{c}\text { Collision } \\
\text { energy }(\mathrm{eV})\end{array}$ \\
\hline Cimetidine & 5.3 & 253 & 94 & 117 & 159 & 10 \\
Erythromycin & 6.1 & 734.4 & 522 & 576 & 158 & 20 \\
Tylosin & 6.3 & 917 & 101 & 772 & 174 & 40 \\
Virginiamycin & 6.3 & 526 & 337 & 355 & 508 & 10 \\
Erythromycin-2- ${ }^{13} \mathrm{C}$ & 6.1 & 736.6 & 578 & 542 & 160 & 20 \\
(Surrogate standard) & 6.1 & & & & & 160 \\
Terbutylazine (ISTD) & 5.9 & 212 & 86 & 114 & 156 & 20 \\
\hline
\end{tabular}

\section{3. 실험방법}

\subsection{1. 표준용액의 제조}

분석물질의 표준용액과 내부표준물질은 메탄올을 사용하여 $1000 \mu \mathrm{g} / \mathrm{mL}$ 또는 $100 \mu \mathrm{g} / \mathrm{mL}$ 이 되도록 저 장용액을 만들었으며, $-20{ }^{\circ} \mathrm{C}$ 에 냉동보관 후 필요시 적절한 농도가 되도록 혼합희석하여 사용하였다.

\subsection{2. 시료보관 및 전처리}

정수장 시료 중 먹는물(정수)에는 잔류 염소가 존재 하여 분석물질의 추출에 방해 또는 분해요소로 작용 한다. 따라서 먹는물 중에 잔류하는 염소를 효과적으로 제거하기 위해서 $4 \mathrm{~L}$ 의 무균 채수병에 시료를 채취한 후 즉시 ascorbic acid와 sodium thiosulfate anhydrous를 각각 $250 \mathrm{mg} / \mathrm{L}, 100 \mathrm{mg} / \mathrm{L}$ 가 되도록 넣어 주었다. 채 취한 시료는 $4{ }^{\circ} \mathrm{C}$ 이하가 유지되고 유기용매의 오염이 없는 냉암소에 보관하였다.

정수 시료 $500 \mathrm{~mL}$ 에 정제용 내부표준물질(surrogate) 인 에리스로마이신-2- ${ }^{13} \mathrm{C}(10 \mu \mathrm{g} / \mathrm{mL}) 25 \mu \mathrm{L}$ 를 첨가한 후 $3.5 \mathrm{M}$ 황산을 사용하여 $\mathrm{pH}$ 를 6으로 조절하였다. Oasis $\mathrm{HLB}(60 \mathrm{mg}, 3 \mathrm{cc})$ 카트리지를 진공감압장치 (vacuum manifold)에 장착한 후 아세토나이트릴 $5 \mathrm{~mL}$ 와 증류수 $5 \mathrm{~mL}$ 를 통과시켜 준비하였다. 준비된 $\mathrm{HLB}$ 카트리지에 시료를 $10 \mathrm{~mL} / \mathrm{min}$ 의 속도로 적재 시킨 후, 적재가 끝난 카트리지에 증류수 $10 \mathrm{~mL}$ 를 흘려주어 씻 어준 후에 질소를 사용하여 카트리지를 건조시킨 다음 $10 \mathrm{mM}$ 암모늄아세테이트 $(\mathrm{pH}$ 6)/아세토나이트릴(50:50, $\mathrm{v} / \mathrm{v})$ 혼합용액 $1 \mathrm{~mL}$ 로 분석물질을 용리시켰다. 이 용리 액에 내부표준물질인 터부틸라진 $(10 \mu \mathrm{g} / \mathrm{mL}) 25 \mu \mathrm{L}$ 를 넣고 $0.45 \mu \mathrm{m}$ 여과지에 여과시킨 후 $1 \mathrm{~mL}$ 갈색 바이알 에 옮겨 LC/ESI-MS/MS에 주입하여 분석하였다(Fig. 2).

\subsection{3. 기기분석 조건}

시료 분리를 위한 $\mathrm{HPLC}$ 의 이동상은 $20 \mathrm{mM}$ 암모 늄아세테이트( $\mathrm{pH}$ 6.5)와 아세토나이트릴이었으며 기
울기 용리방법을 사용하였는데 초기 유기용매는 $5 \%$ 이었고 3 분 동안에 $85 \%$ 로 선형적으로 변화시킨 후 $85 \%$ 에서 6 분 동안 유지하였다. 이동상의 유속은 0.3 $\mathrm{mL} / \mathrm{min}$ 이었으며 시료 주입양은 $10 \mu \mathrm{L}$ 이었다.

질량분석기는 전기분무이온화(ESI) 양이온(+) 모드 와 MRM (multiple reaction monitoring) 방법을 사용하 였으며, capillary voltage는 $4 \mathrm{kV}$, 분무기체(질소)의 온 도는 $350^{\circ} \mathrm{C}$, 기체 유량은 $10 \mathrm{~L} / \mathrm{min}$ 이었으며, $\mathrm{MRM}$ 분석을 위한 이온들은 Table 1에 나타내었다.

\section{3. 결과 및 고찰}

\section{1. $\mathrm{HPLC} / \mathrm{ESI}-\mathrm{MS} / \mathrm{MS}$ 스펙트럼}

$\mathrm{LC} / \mathrm{MS} / \mathrm{MS}$ 에서 시메티딘과 에리스로마이신은 5.3 분과 6.1 분에서 용리되었고, 타이로신과 버지니아마이 신은 6.3분에서 공용리(co-elution)되었으나 질 량스펙 트럼이 달랐기 때문에 정량 - 정성 분석에는 문제가 없 었다(Table 1).

텐뎀 질량분석기에서 의약물질들의 정량이온과 정 성이온들을 얻기 위해서 다음과 같은 절차가 수행되 었다. 먼저, ESI 양이온(+) 모드를 사용하여 full scan을 통해서 질량스펙트럼을 얻은 후, 기준이온 (base ion)을 선구이온(precursor ion)으로 선택하였 다. 선택된 선구이온에 최적의 충돌 에너지(collision energy)를 가함으로써 안정되고 감도 좋은 생성이온 (product ion)을 만들어서 정량 및 정성확인에 사용 할 수 있었다.

4종 의약물질 모두가 $[\mathrm{M}+\mathrm{H}]^{+}$이 선구이온으로 선택 되었는데 시메티딘은 $\mathrm{m} / \mathrm{z} \mathrm{253}$, 에리스로마이신은 $\mathrm{m} / \mathrm{z}$ 734.4 , 타이로신은 $\mathrm{m} / \mathrm{z}$ 917, 버지니아마이신은 $\mathrm{m} / \mathrm{z}$ 526 이었다. 생성이온들 중에서 가장 세기가 큰 이온이 정량이온(quantitation ion)으로 선택되었으며, 차순 크 기의 이온들이 확인이온(confirmation ion)으로 선택되 어 정성확인을 하는데 사용되었다(Fig. 3). 


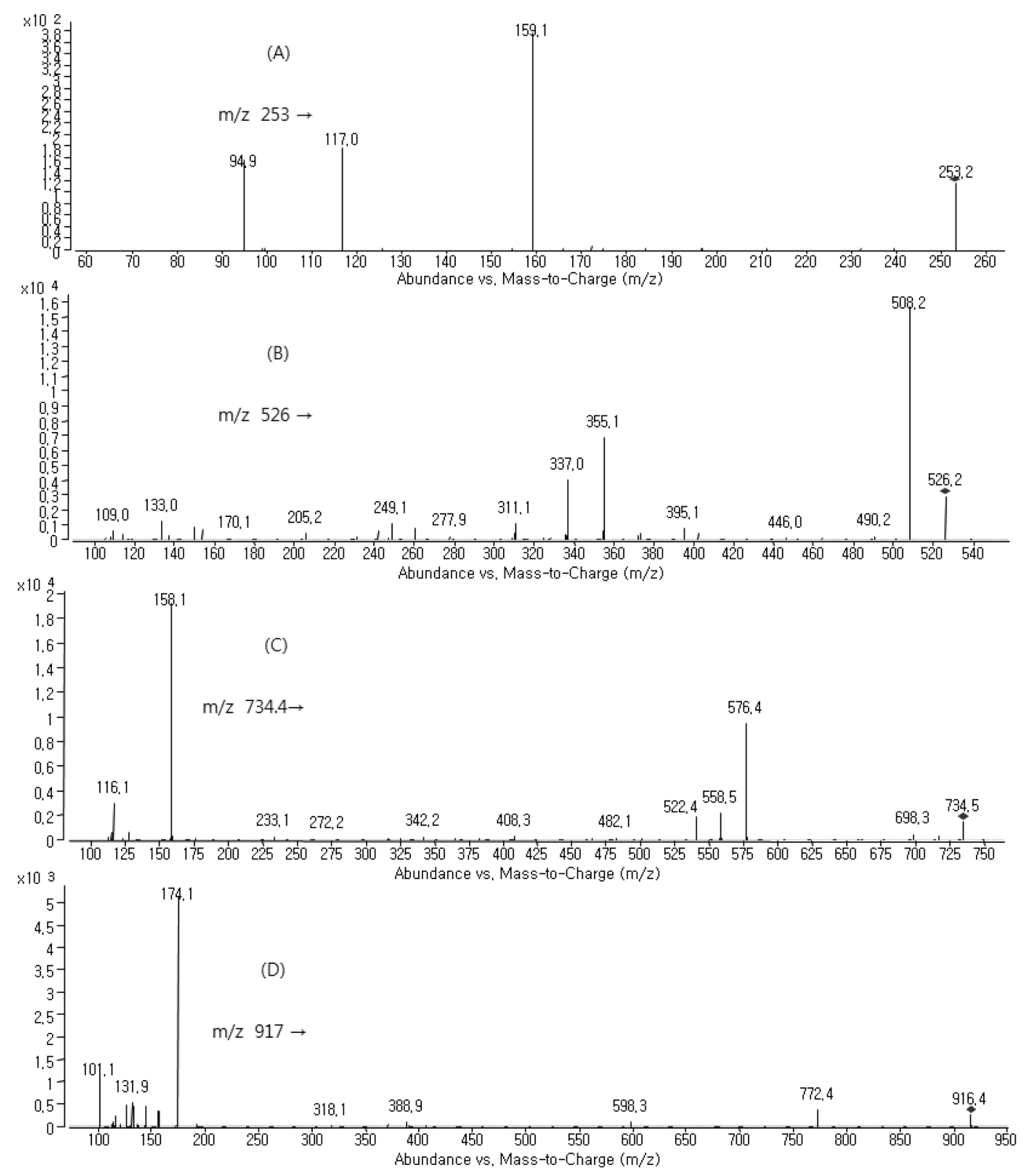

Fig. 3. ESI product ion spectra of (A): cimetidine; (B): virginiamycin; (C) erythromycin; and (D) tylosin from spiked blank drinking water.

\section{2. 크로마토그램}

바탕하수에 분석대상 표준물질을 소량첨가한 후 확 립된 시료전처리 방법에 따라서 전처리를 거친후 $\mathrm{MRM}$ 모드로 분석한 TIC (total ion chromatogram)과 EIC (extracted ion chromatogram) 결과를 Fig. 4에 나 타내었다. Cimetidine은 5.3분, erythromycin은 6.1 분에 잘 분리되어 검출되었는데 tylosin과 virginiamycin은 머무름시간이 6.3 분으로 동일하였지만 특성이온이 다 름으로 인해 정성 및 정량에는 별다른 문제가 없었다.
분석방법의 특이성(선택성)을 나타내기 위하여 바탕 정수에 대한 각 분석물질의 MRM 분석 크로마토그램 을 Fig. 5에 나타내었다. 크로마토그램에서 보는바와 같 이 각 분석물질이 검출되는 머무름 시간에는 해당 특성 이온들에 기인한 피이크들이 거의 검출되지 않았다.

\section{3. 검량선, 회수율, 정밀도}

정수 중에 잔류하는 의약물질의 양을 측정하기 위 해서, 시료 중에서 농도가 $0.005 \sim 2.0 \mathrm{ng} / \mathrm{mL}$ 의 범위가 


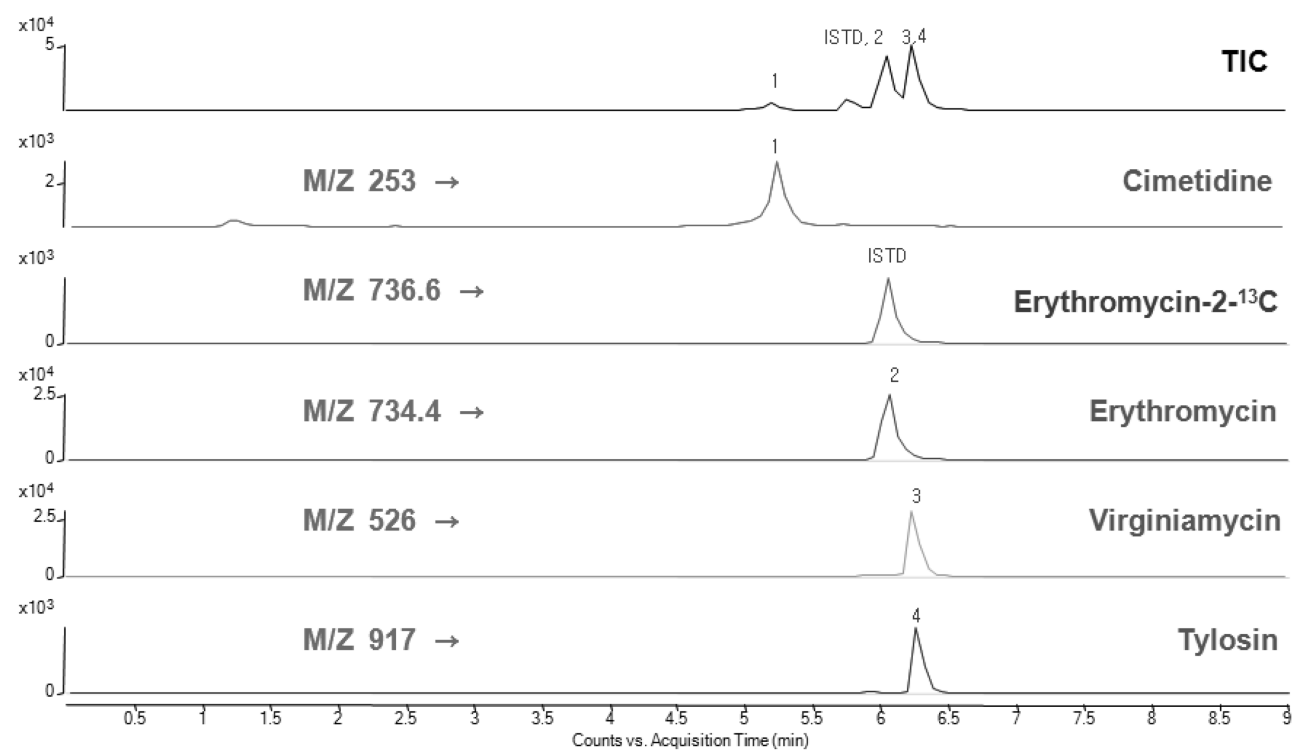

Fig. 4. Chromatograms for TIC (total ion chromatogram) and extracted ion chromatograms (cimetidine, erythromycin, virginiamycin and tylosin) in spiked treated water sample $(2 \mathrm{ng} / \mathrm{mL})$.
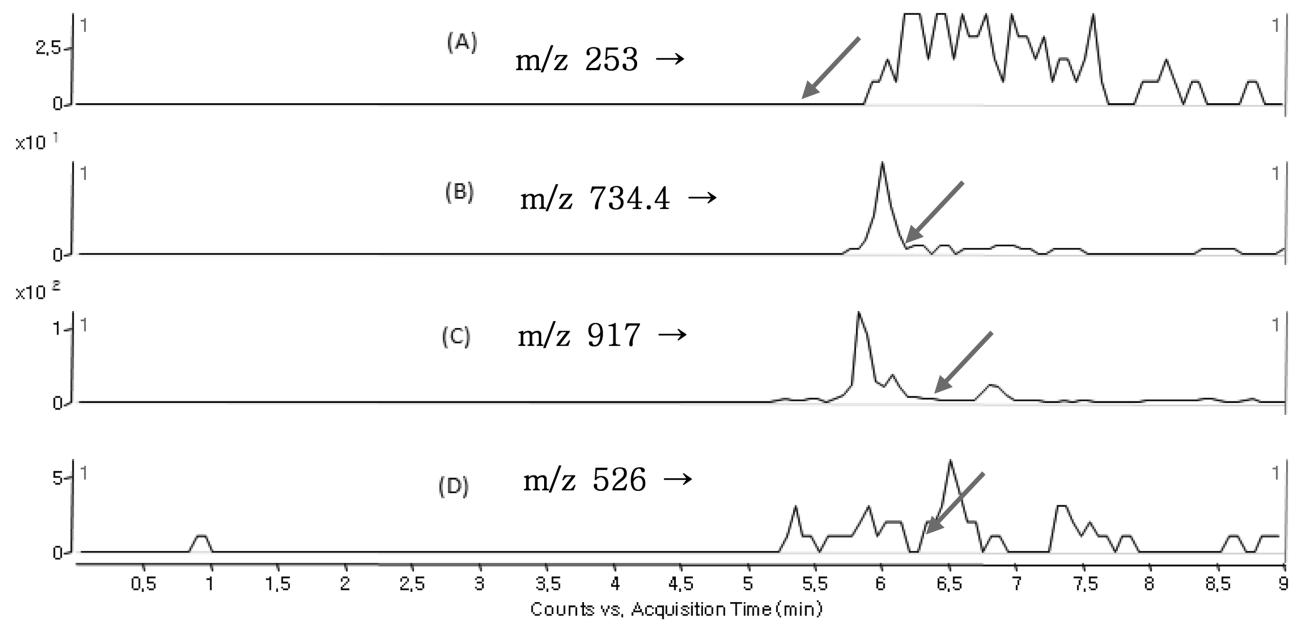

Fig. 5. Chromatograms for (A): cimetidine; (B): erythromycin; (C): virginiamycin; and (D) tylosinin in blank treated water sample.

되도록 표준물질을 바탕 정수에 소량 첨가(spike)하여 시료 전처리 과정을 거친 후 LC/ESI-MS/MS로 분석 하였으며 내부표준법을 사용하여 검 량선을 작성하였 다. 검량선의 범위는 의약물의 정량한계에 따라 다르 게 작성되었으며, $0.005-2.0 \mathrm{ng} / \mathrm{mL}$ 농도를 작업구간으 로 설정하였으며 상관계수 $\left(\mathrm{r}^{2}\right)$ 가 0.995 이상으로 좋은 직선성을 나타내었다(Table 2).

바탕 정수에서의 농도가 $0.1 \sim 2.0 \mathrm{ng} / \mathrm{mL}$ 되도록 의 약물질 표준용액을 소량 첨가한 후, 시료 전처리를 거
친 값과 거치지 않은 표준물질 농도의 절대치를 비교 함으로써 절대 회수율을 측정하였다. 세 가지 농도에 서 측정한 회수율은 $37.7 \sim 118.1 \%$ 의 값을 나타내었지 만, 시메티딘의 경우 대체적으로 낮은 회수율(37.7 $48.1 \%)$ 을 나타내었다. 정밀도를 나타내는 상대표준편 차(RSD)는 6.6 17.7\%로써 낮은 농도이지만 대체적으 로 양호한 정밀도를 보여주었다. Table 3에 4종 의약 물질의 정수 중의 검출한계와 정량한계, 절대 회수율 및 정밀도를 나타내었다. 
Table 2. Calibration equation and coefficient of correlation for the quantification

\begin{tabular}{lccc}
\hline \hline Pharmaceuticals & $\begin{array}{c}\text { Concentration range } \\
(\mathrm{ng} / \mathrm{mL})\end{array}$ & Linear equation & Coefficient of correlation $\left(\mathrm{r}^{2}\right)$ \\
\hline Cimetidine & $0.1 \sim 2.0$ & $\mathrm{y}=0.8999 \mathrm{x}-0.0055$ & 0.9950 \\
Erythromycin & $0.005 \sim 2.0$ & $\mathrm{y}=3.9761 \mathrm{x}+0.0144$ & 1.0000 \\
Tylosin & $0.005 \sim 2.0$ & $\mathrm{y}=1.8150 \mathrm{x}-0.0146$ & 0.9991 \\
Virginiamycin & $0.1 \sim 2.0$ & $\mathrm{y}=0.7918 \mathrm{x}-0.0539$ & 0.9951 \\
\hline
\end{tabular}

Table 3. Absolute recovery, limit of detection (LOD), limit of quantitation (LOQ) and precision

\begin{tabular}{|c|c|c|c|c|c|}
\hline Pharmaceuticals & $\begin{array}{c}\text { LOD* }^{*} \\
(\mathrm{pg} / \mathrm{mL})\end{array}$ & $\begin{array}{l}\mathrm{LOQ}^{* *} \\
(\mathrm{pg} / \mathrm{mL})\end{array}$ & $\begin{array}{l}\text { Conc. } \\
\text { (ng/mL) }\end{array}$ & $\begin{array}{c}\text { Recovery } \\
(\%)\end{array}$ & $\begin{array}{c}\operatorname{RSD}(\%) \\
(n=3)\end{array}$ \\
\hline \multirow{3}{*}{ Cimetidine } & \multirow{3}{*}{74.8} & \multirow{3}{*}{249.7} & 0.7 & 47.0 & 15.2 \\
\hline & & & 1.0 & 37.7 & 6.6 \\
\hline & & & 2.0 & 48.1 & 11.5 \\
\hline \multirow{3}{*}{ Erythromycin } & \multirow{3}{*}{1.6} & \multirow{3}{*}{5.5} & 0.1 & 93.2 & 4.4 \\
\hline & & & 1.0 & 105.6 & 9.1 \\
\hline & & & 2.0 & 118.1 & 6.9 \\
\hline \multirow{3}{*}{ Tylosin } & \multirow{3}{*}{4.1} & \multirow{3}{*}{13.8} & 0.1 & 64.7 & 4.9 \\
\hline & & & 1.0 & 67.6 & 12.1 \\
\hline & & & 2.0 & 78.4 & 9.8 \\
\hline \multirow{3}{*}{ Virginiamycin } & \multirow{3}{*}{38.7} & \multirow{3}{*}{129.0} & 0.7 & 106.3 & 17.7 \\
\hline & & & 1.0 & 85.3 & 8.5 \\
\hline & & & 2.0 & 67.8 & 4.7 \\
\hline
\end{tabular}

*LOD : $3 \mathrm{~s} / \mathrm{m}, * *$ LOQ $: 10 \mathrm{~s} / \mathrm{m}$

각 의약물질의 검출한계(LOD)와 정 량한계(LOQ) 는 바탕정수에 표준물질을 소량 첨가함으로 구하였 으며 그 절차는 다음과 같다. 먼저, 추정한 검출한계 에 해당하는 농도로 표준물질을 각 물질이 검출된 이력이 없는 바탕 정수 $(\mathrm{n}=7)$ 에 소량첨가한 후 확립 된 시료전처리방법에 따라서 전처리 한 후 검량선으 로부터 농도를 측정하였다. 측정한 값으로부터 표준 편차(s)를 구하고, 검량선으로부터 얻은 기울기 $(\mathrm{m})$ 값을 바탕으로 검출한계(LOD)는 $3 \mathrm{~s} / \mathrm{m}$, 정량한계 $(\mathrm{LOQ})$ 는 $10 \mathrm{~s} / \mathrm{m}$ 으로 계산하여 구하였다. 계산된 농 와 $\mathrm{LOQ}$ 에 해당하는 농도를 다시 바탕 정수에 소량 첨가 하여 피이크를 확인하였다. 에리스로마이신의 경우 $\mathrm{LOD}$ 와 $\mathrm{LOQ}$ 가 $1.6 \mathrm{pg} / \mathrm{mL}$ 와 $5.5 \mathrm{pg} / \mathrm{mL}$ 를 나 타내었으며 시메티딘의 경우 4가지 물질중 가장 높 은 검출한계 $(74.8 \mathrm{pg} / \mathrm{mL})$ 와 정량한계 $(249.7 \mathrm{pg} / \mathrm{mL})$ 를 나타내었다(Table 3).

2009년 8-9월과 11월에 4대강 유역 정수장 20지 점에 대해서 원수와 처리수에 대해서 모니터링한 결 과 4 종류 의약물질의 정량한계 이상으로 검출된 예 는 없었다.

\section{4. 결 론}

본 논문에서는 HPLC/ESI-MS/MS를 이용하여 먹는 물(정수) 중에 잔류하는 의약물질 4종(버지니아마이신, 에리스로마이신, 타이로신 및 시메티딘)을 동시에 분석 하는 방법을 확립하였다. 정수에는 염소성분이 다량 존 재하는데 ascorbic acid와 sodium thiosulfate anhydrous 를 첨가함으로써 시료 채취 후 추가적인 분해나 분석 시 방해를 막을 수 있었다.

확립된 분석방법은 감도 $(5.5 ~ 249.7 \mathrm{pg} / \mathrm{mL})$ 가 좋고, 정밀도가 높은 방법으로써 정수 중에 잔류하는 의약 물질의 효과적인 분석방법이며, 전국의 대표적인 정수 장에서 채취한 실제 먹는물을 분석한 결과 모두 정량 한계 이하이었다.

\section{감사의 글}

본 연구는 국립환경과학원의 2009년도 잔류의약물 질 분석방법 연구 및 실태조사(II) 사업의 지원으로 이 루어진 것이며, 경기대학교 특성화사업단의 LC/MS/ 
$\mathrm{MS}$ 를 사용하였음.

\section{참고문헌}

1. K. Kummerer, 'Pharmaceuticals in the environment', 51nd Ed., Vol. 35, 265, Springer-Verlag, Berlin-Heidelberg-New York-London, 2001.

2. D. W. Kolpin, E. T. Furlong, M. T. Meyer, E. M. Thurman, S. D. Zaugg, L. B. Barber and H. T. Buxton, Environ. Sci. Technol., 36, 1202-1211(2001).

3. X. S. Miao and C. D. Metacalfe, Anal. Chem., 75, 3731-3738(2003).

4. 국립환경과학원, 잔류의약물질 분석방법 및 실태조 사(II), (2009).

5. M. Lindsey, M. Meyer and E. M. Thurman, Anal.
Chem., 73, 4640-4646(2001).

6. M. J. Hilton and K. V. Thomas, J. Chromatogr. A, 1015, 129-141(2003).

7. C. Hao, L. Lissemore, B. Nguyen, S. Kleywegt, P. Yang and K. Solomon, Anal. Bioanal. Chem., 384, 505513(2006).

8. F. Sacher, F. T. Lange, H-J. Brauch and I. Blankenhorn, J. Chromatogr. A, 938, 199-210(2001).

9. W. A. Moats and L. Leskinen, J. Agric. Food Chem., 36(6), 1297-1300(1988).

10. T. H. Tsai, H. H. Tung, L. C. Hung, F. C. Cheng and C. F. Chem, J. Liq. Chromatogr. Relat. Technol., 23(10), 1599-1608(2000).

11. P. M. Gerk, C. Y. Oo, E. W. Paxton, J. A. Moscow and P. J. McNamara, JETP Lett, 296, 175-180(2001). 